\section{BRAZIULIAN JOURNAL}

OF MEDICAL AND BIOLOGICAL RESHARCH

www.bjournal.com.br
ISSN 0100-879X

Volume 43 (9) 812-913 September 2010

BIOMEDICAL SCIENCES

AND

CLINICAL INVESTIGATION

Braz J Med Biol Res, September 2010, Volume 43(9) 899-905

doi: 10.1590/S0100-879X2010007500085

Morphine infusions into the rostrolateral periaqueductal gray affect maternal behaviors

L.M. Moura, N.S. Canteras, M.H. Sukikara and L.F. Felicio

The Brazilian Journal of Medical and Biological Research is partially financed by
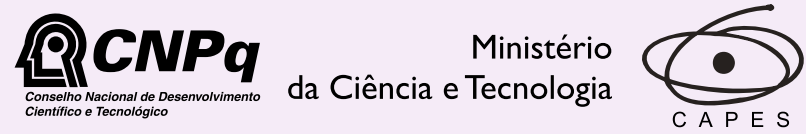

Ministério da Educação

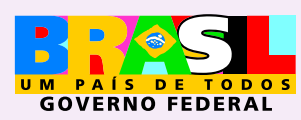

DFAPESP

Institutional Sponsors
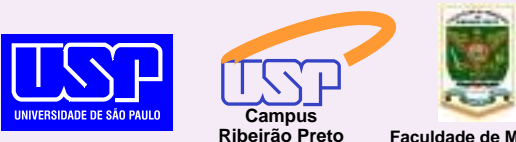

Ф SHIMADZU

GE Healthcare
Hotsite of proteomics metabolomics developped by: 


\title{
Morphine infusions into the rostrolateral periaqueductal gray affect maternal behaviors
}

\author{
L.M. Moura ${ }^{1}$, N.S. Canteras $^{2}$, M.H. Sukikara ${ }^{1}$ and L.F. Felicio ${ }^{1}$ \\ 1Departamento de Patologia, Faculdade de Medicina Veterinária e Zootecnia, \\ ${ }^{2}$ Departamento de Anatomia, Instituto de Ciências Biomédicas, \\ Universidade de São Paulo, São Paulo, SP, Brasil
}

\begin{abstract}
It is well established that morphine inhibits maternal behaviors. Previous studies by our group have shown activation of the rostrolateral periaqueductal gray (rIPAG) upon inhibition-intended subcutaneous injections of morphine. In this context, we demonstrated that a single naloxone infusion into the rIPAG, following this opioid-induced inhibition, reactivated maternal behaviors. Since these data were obtained by using peripheral morphine injections, the present study was designed to test whether morphine injected directly into the rIPAG would affect maternal behaviors. Our hypothesis that morphine acting through the rIPAG would disrupt maternal behaviors was confirmed with a local infusion of morphine. The mothers showed shorter latency for locomotor behavior to explore the home cage $(P=0.049)$. Inhibition was especially evident regarding retrieving $(P=0.002)$, nest building $(P=0.05)$ and full maternal behavior $(P=0.023)$. These results support the view that opioidergic transmission plays a behaviorally meaningful inhibitory role in the rostrolateral PAG.
\end{abstract}

Key words: PAG; Maternal behaviors; Lactation; Opiate; Active behavior

\section{Introduction}

Neurobiological studies of maternal behavior indicate the involvement of numerous brain regions (1). The behavioral repertoire of the mother towards her pups includes pro-nurturing activities such as retrieval, licking, and nest building, all of which precede prolonged periods of quiescent nursing (2). Retrieval and grouping are necessary for nursing activities, as is nest building, which ensures a safety area (1).

Opioid systems are plastic and adaptive and are functionally modulated by the reproductive experience (3-6). It is well established that opioids disrupt maternal behaviors. Both morphine and $\beta$-endorphin, the latter of which is an endogenous opioid, have inhibitory effects on the maintenance of maternal behaviors (7-10). Subcutaneous injections of opioids have indicated a possible involvement of various neuronal systems and brain regions in maternal behavior (11).

Morphine sulfate infusions into the medial preoptic area (MPOA) reduced maternal behavior, a receptor-mediated effect (12). Another study showed an inhibitory influence of morphine when injected intracerebroventricularly. Morphine works inside the MPOA by prompting aversive behavior towards pups (13). There are connections between the MPOA and the periaqueductal gray (PAG) $(1,14)$.

The PAG does not have homogeneous neuronal connections but rather regional specialization (15), and is divided into longitudinal columns (16). This topographic organization is involved in the development of different types of behaviors $(15,16)$. Thus, the effects of direct application of morphine into the PAG vary according to the different regions (17).

Critical levels of opioidergic stimulation by subcutaneous morphine injections in a protocol of sensitization inhibited maternal behaviors and induced activation of the rostrolateral PAG (rIPAG) (18). This was a pattern expressed through the Fos protein in this region when inhibition was in effect. Furthermore, when the opioid antagonist naloxone was infused into the lateral PAG, maternal care was restored, suggesting that the PAG plays a role in the opioid-induced inhibition of maternal behaviors (18).

The objective of the present study was to determine

Correspondence: L.M. Moura, Laboratório de Neurociências e Comportamento, FMVZ, USP, Av. Orlando Marques de Paiva, 87 , 05508-900 São Paulo, SP, Brasil. Fax: +55-11-3091-7829. E-mail: lummoura@gmail.com

Received December 21, 2009. Accepted August 11, 2010. Available online August 27, 2010. Published September $13,2010$. 
whether morphine infused directly into the rIPAG has any effect on maternal behaviors. Although previous studies from our laboratory have demonstrated the involvement of the IIPAG in maternal behaviors, it remains unclear whether this restricted area alone, in a pharmacological paradigm, is capable of inhibiting the correct caring behaviors towards the pups. To clarify this point, different components of full maternal behavior were evaluated, demonstrating that parameters such as nest building, retrieving and pup grooming were disrupted.

\section{Material and Methods}

\section{Animals}

Female rats were tested for maternal behaviors. Subjects were adult Wistar nulliparous female rats weighing 180$200 \mathrm{~g}$ and approximately 90 days of age at the beginning of the experiments. In all experiments, the females were timemated by placing them with sexually experienced males. The day on which sperm was observed in the vaginal lavage was designated day 1 of pregnancy. Pregnant females were individually housed in opaque polypropylene cages (41 $\mathrm{x}$ $34 \times 16 \mathrm{~cm}$ ) containing approximately $1.0 \mathrm{~L}$ medium-grade pine flakes. Food and water were available ad libitum to the animals in light- (6:00-18:00 h) and temperature-controlled $\left(20-25^{\circ} \mathrm{C}\right)$ testing rooms. After giving birth (day 0 of lactation), females were left with their litters (culled to eight pups on day 1 of lactation) until testing for maternal behaviors on day 6 of lactation. Animals were maintained in accordance with the guidelines of the Committee on Animals of the Colégio Brasileiro de Experimentação Animal (COBEA) and the Committee on Care and Use of Laboratory Animal Resources National Research Council, USA.

\section{Stereotaxic surgery}

From days 14 to 16 of pregnancy, the animals were anesthetized with a mixture of ketamine (Vetaset, Forte Dodge Laboratory, Brazil) and xylazine (1:2 v/v, $1 \mathrm{~mL} / \mathrm{kg}$ body weight; Rompum, Bayer, Brazil), and then placed in a small animal stereotaxic instrument (Kopf Instrument, Model 900 , USA). The bone of the skull was then exposed and a small window opened, exposing the dura mater. On one side of the brain a stainless-steel guide cannula (Plastics One Inc., USA) was implanted into the rIPAG (AP $=-6.8 \mathrm{~mm}$ from bregma, $\mathrm{ML}=0.6 \mathrm{~mm}, \mathrm{DV}=5.3 \mathrm{~mm}$ from the surface of the brain) (19). The guide cannula measured $4.3 \mathrm{~mm}$ in length and the probe $5.3 \mathrm{~mm}$ in length. Thus, the infusion syringe also measured $5.3 \mathrm{~mm}$ in length. The cannula was fixed with polyacrylic cement and anchored to the skull with stainless-steel screws.

\section{Drug administration}

To observe the effects of central morphine injections on opioid-induced inhibition of maternal behaviors in lactating rats, the following groups were used: 1) animals receiving an acute central injection of morphine sulfate $6 \mu \mathrm{g} / 0.6 \mu \mathrm{L}$ (Dimorf $^{\circledR}$, Cristália Lab., Brazil) in their rIPAGs $(\mathrm{N}=16)$ - morphine-treated group, 2) animals receiving an acute central injection of saline $(0.6 \mu \mathrm{L}, 0.9 \%)$ in their rIPAGs ( $N$ =15) - saline-treated group.

For drug administration, the animals were gently immobilized, while a removable injector was inserted into the guide cannula until it was $1 \mathrm{~mm}$ longer than the guide tip (according to DV coordinate). The injector was linked to a $1-\mu \mathrm{L}$ Hamilton syringe attached to an infusion pump (Harvard Apparatus, USA). The solution (morphine or saline) was infused for $30 \mathrm{~s}$. The infusion cannula was left in the guide cannula for an additional $30 \mathrm{~s}$ after infusion.

\section{Maternal behavior testing}

On the 6th day of lactation, all pups, water and food were removed from the home cage, and the nests destroyed. Thirty minutes later, the dams received the acute dose of morphine or saline and $30 \mathrm{~min}$ after that, all 8 pups were placed back in the cage in a haphazard pattern, at which point maternal behavior testing was started. Latencies, in seconds, for pup contact, retrieval, grouping, nest building, nursing, kyphosis, and full maternal behavior (FMB) responses were scored. Animals were scored as fully maternal (FMB) if they had retrieved all 8 pups to the previously constructed nest and nursed over them in a kyphotic position for 3 consecutive minutes. Events were observed continuously during the first $30 \mathrm{~min}$ (or $1800 \mathrm{~s}$ ), and were recorded on first observation. Two other observations were made: one at $45 \mathrm{~min}$ (or $2700 \mathrm{~s}$ ) and the other at $60 \mathrm{~min}$ (or $3600 \mathrm{~s}$ ).

\section{Histological demonstration of cannula placement}

At the end of the behavioral testing, all dams were killed with an overdose of pentobarbital and transcardially perfused with saline followed by $10 \%$ formalin. The brains were immediately removed and postfixed in the same fixative containing $20 \%$ sucrose. The brains were then frozen, and cut into $30-\mu \mathrm{m}$ thick serial sections on a frontal plane. The sections were mounted on gelatin-coated slides and stained with thionine. Only the animals with correct cannula placement were considered for this study (Figure 1).

\section{Statistical analysis}

For parameters such as FMB, retrieval and nest building, the values from each experimental group were arranged in a contingency $2 \times 2$ table and analyzed by the Fisher exact test. Other parameters, such as total time and scores of latencies, were analyzed by the nonparametric Mann-Whitney U-test. Data are reported as median and interquartile ranges $\left(Q_{1}\right.$ $Q_{3}$ ). Regarding the latency parameters, we attributed scores for statistical analysis, excluding latency for locomotor behavior to explore the home cage, as follows: $1=0-300 \mathrm{~s}, 2$ $=301-600 \mathrm{~s}, 3=601-900 \mathrm{~s}, 4=901-1200 \mathrm{~s}, 5=1201-1500$ $\mathrm{s}, 6=1501-1800 \mathrm{~s}, 7=>1801 \mathrm{~s}(20)$. This transformation 

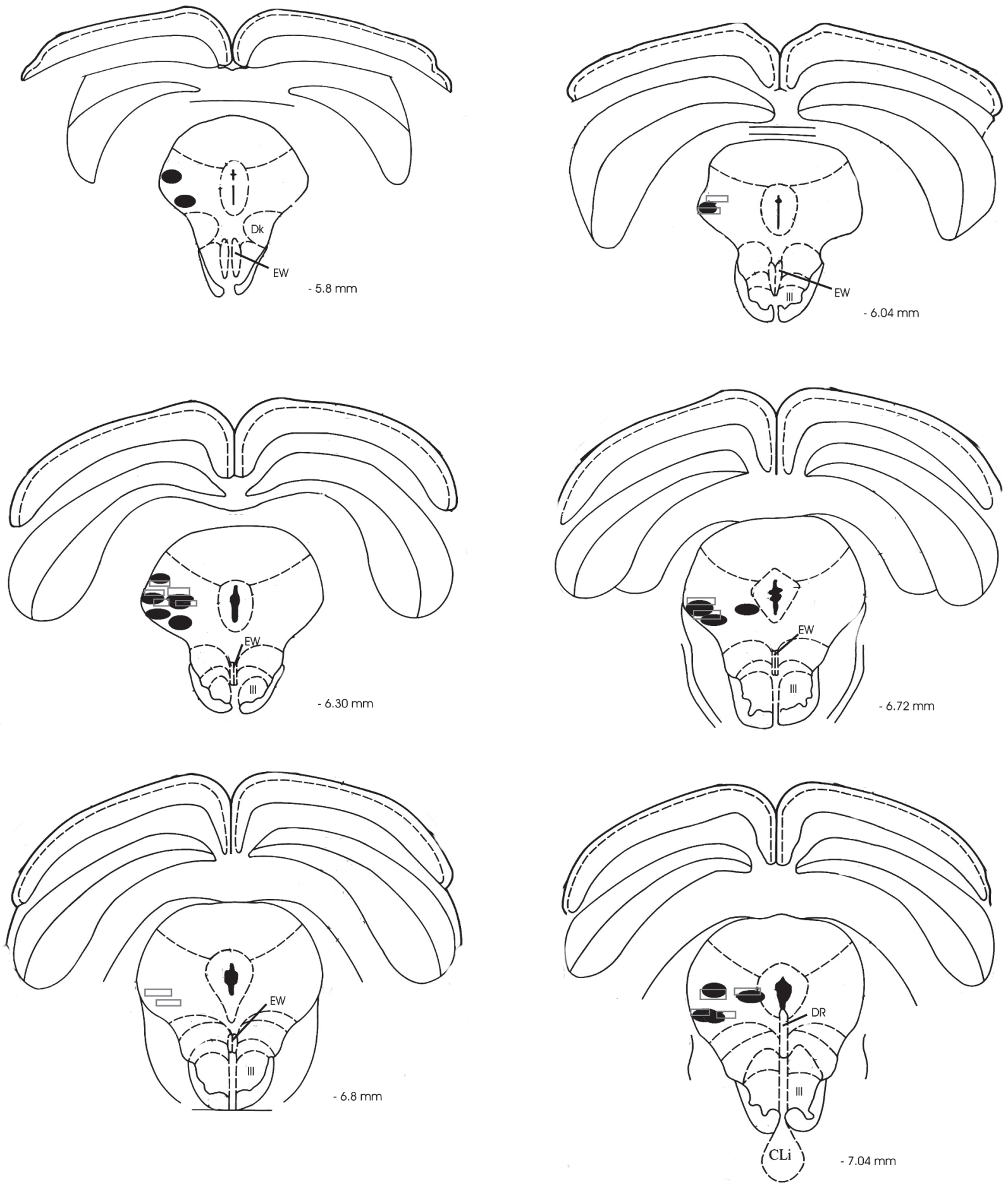

Figure 1. Diagrams, modified from Ref. 19, show the main morphine injection sites (black ellipses) and the main saline injection sites (gray rectangles) in the rostrolateral periaqueductal gray (extending from $5.8 \mathrm{~mm}$ to $7.04 \mathrm{~mm}$ posterior to bregma). Due to overlapping, the number of points illustrated may seem smaller than the number of rats actually injected in this study. CLi $=$ caudal linear nucleus raphe; Dk = nucleus Darkschewitisch; DR = dorsal raphe nucleus; EW = Edinger-Westphal nucleus; III = oculomotor nucleus. 
allowed us to include in our analysis those animals that did not perform the behavioral parameter within the 30 min observation period. This missing behavior ranks the dam 7th (maximum score) in the present analysis using a well-established ranking protocol.

\section{Results}

The experimental group treated with morphine showed significant decreases in the percent of animals displaying retrieving $(P=0.002)$, nest building $(P=0.009)$ and $F M B$ $(P=0.003$; Figure 2).

Animals subjected to treatment with morphine displayed significantly longer latencies for retrieving the last pup $(P=0.002)$. Since not all morphine-treated dams retrieved all pups, we adopted a maximum score for this situation: 7 (for a better understanding of the scores, see explanation in Material and Methods). Since the animals treated with morphine retrieved the same pups several times, only the latency for retrieving all pups was compared to the control group. They showed statistically significant differences in the following parameters: nest building $(P=0.05)$; pup grooming $(P=0.046)$; $F M B(P=$ $0.023)$; shorter latency for locomotor behavior to explore the home cage ( $P=0.049$; Figure 3 ).

\section{Discussion}

It has been shown that unilateral naloxone infusions into the rIPAG of morphine-infused dams are sufficient to restore maternal behaviors (18). At the end of pregnancy, unilateral cytotoxic lesions induced by $\mathrm{N}$-methyld-aspartate (NMDA) in the same area had reversed morphine-inhibition of maternal behaviors when dams were tested only with pups (20). In the present study, a single unilateral infusion of morphine into the rIPAG was sufficient to inhibit parameters involved in maternal behaviors. This central injection disrupted full maternal behavior, whose expression hinges upon segmented parameters. Parameters such as the occurrence of kyphosis were not affected, although not displayed over all 8 pups, reflecting the disruption of the important earlier behaviors of litter retrieval and grouping. The rats that did retrieve the pups showed longer retrieval latencies. Usually a morphine-treated dam carries its pups several times but soon after releases them and tends to display increased exploratory behavior. The short latency for locomotor behavior to explore the home cage reveals a significant engagement in this activity in likely detriment of pup retrieval or nest building, which provides a secure place for displaying all nursing behaviors.

Our results were consistent with the reports that nursing kyphosis is related to the ventrolateral PAG $(2,21,22)$. There is no role for this parameter in the rostral PAG (22). Lesions in the ventrolateral PAG reduce kyphosis by $85 \%$
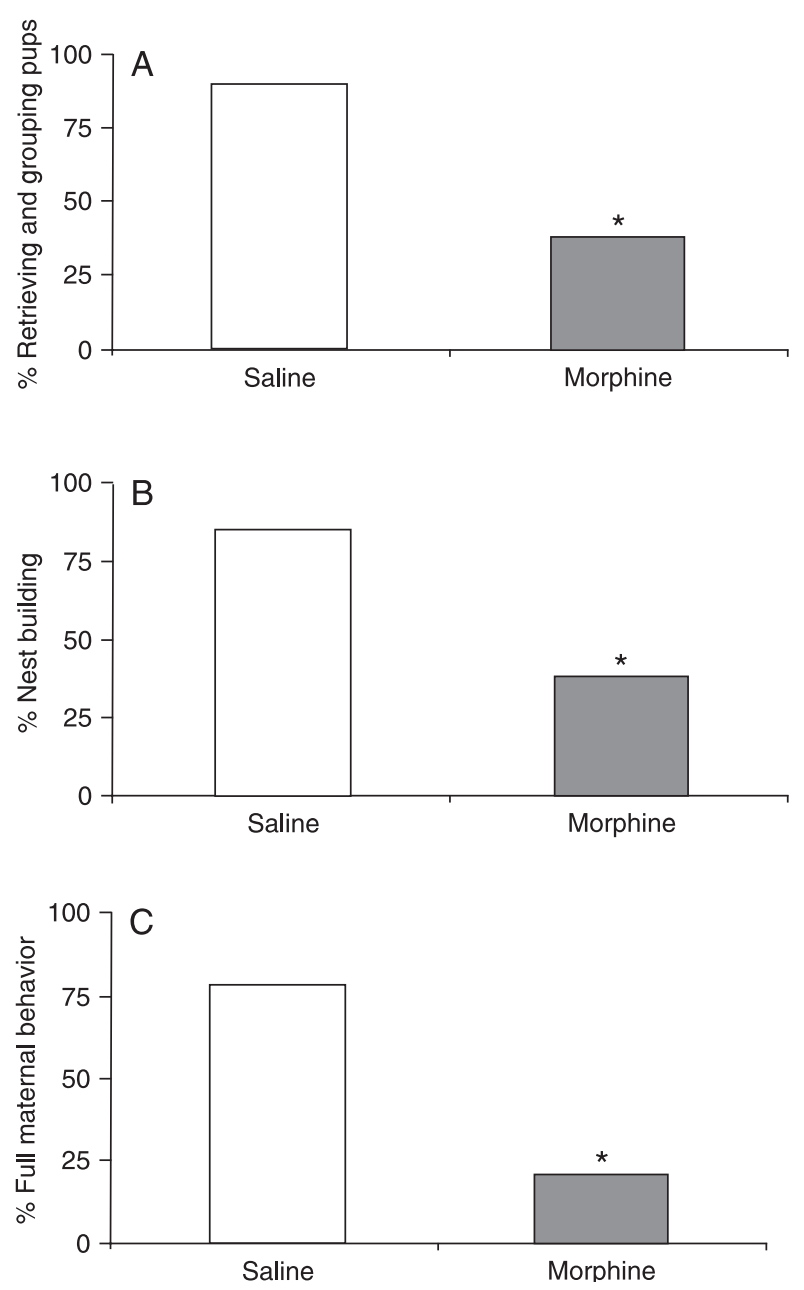

Figure 2. $A$, Retrieving and grouping pups; $B$, nest building; $C$, full maternal behavior. Data are reported as percent of animals displaying each behavior. ${ }^{*} \mathrm{P}<0.01$ compared to saline treatment, respectively (Fisher test).

$(2,22)$, whereas lesions in the rostral PAG do not inhibit kyphosis (22).

Recently, it was demonstrated that the PAG is an area susceptible to opioids and expresses the encoded $\mu$-opioid receptor Oprm1 and other genes related to $\mathrm{K}$ and $\delta$ receptors, and that morphine specificity in this area $(23,24)$ is supported by the observation that infusions of naloxone into this area restore maternal behaviors (18). In the present study, therefore, we evaluated the behavioral effects of local opioidergic stimulation of the rIPAG. In another study, dams submitted to pre-treatment with morphine during late pregnancy and acutely challenged with a peripheral injection of this drug during lactation had their maternal behaviors reestablished by infusion of either naloxone or cholecystokinin (CCK) into the rIPAG $(18,25)$. Curiously, either naloxone or CCK can 
reverse opioid-induced inhibition of maternal behaviors when injected into the MPOA. This suggests that opioid mechanisms controlling maternal behaviors in the PAG might have patterns of receptor dynamics and multipeptidergic control that are similar to those described for other brain areas $(8,9,18,25)$.

Low doses of subcutaneous morphine enhance preda-
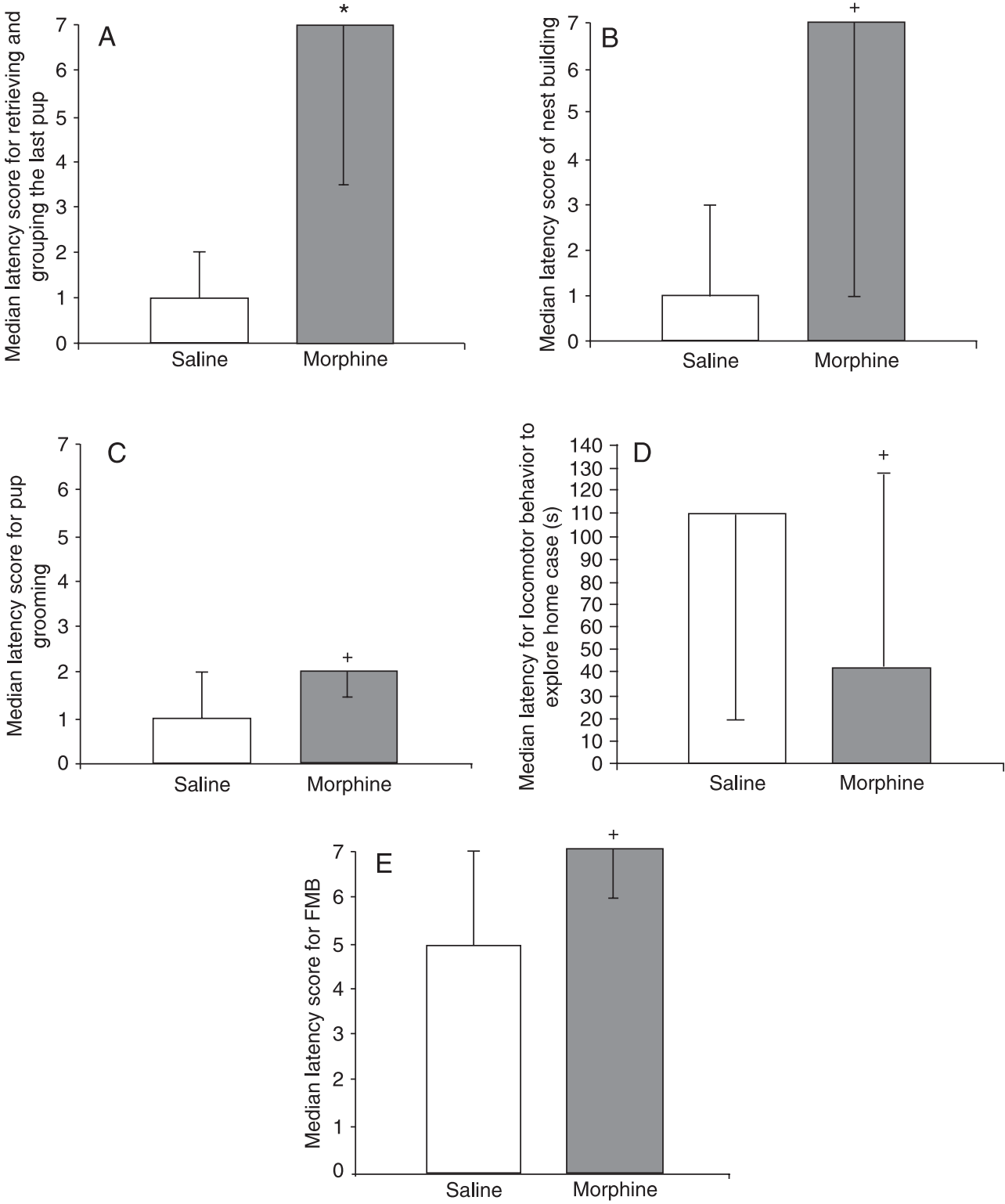

Figure 3. $A$, Median latency score for retrieving and grouping the last pup; $B$, median latency score of nest building; $C$, median latency score for pup grooming; $D$, median latency for locomotor behavior to explore the home cage (saline-treated group, $\mathrm{N}=15$; morphine-treated group, $\mathrm{N}=14$ ); $\mathrm{E}$, median latency score for full maternal behavior (FMB). Data are reported as median and interquartile range $\left(Q_{1}-Q_{3}\right)$. ${ }^{*}<0.005$ and ${ }^{+} \mathrm{P} \leq 0.05$ compared to saline treatment (Mann-Withney U-test). Scores: $1=300 \mathrm{~s}, 2=301-600 \mathrm{~s}, 3=$ $601-900 \mathrm{~s}, 4=901-1200 \mathrm{~s}, 5=1201-1500 \mathrm{~s}, 6=1501-1800 \mathrm{~s}, 7=>1801 \mathrm{~s}$ (except for median latency for locomotor behavior to explore home cage). 
Previous reports have supported a role for the rostral PAG in predatory hunting (27). The rIPAG appears to be importantly driven by medial prefrontal cortical areas involved in controlling attention-related and decision-making processes. In addition, it is known that the rIPAG receives amygdalar, hypothalamic, and brainstem neurons related to feeding, drinking, or hunting behavioral responses. Lactating rats acutely challenged with morphine, under disrupted maternal behavior, present a significantly increased Fos expression in the lateral PAG at the level of the oculomotor nucleus (18). This pattern of activation expressed in the rIPAG may reveal a role of this area in exploratory behavior (20) and an activation pattern similar to that occurring during predatory hunting, considering that morphine challenge induces this behavior (26).

Recently, it was observed that ascending fibers from the rIPAG provide a substantial input to the lateral hypothalamic area, and also, to a lesser extent, to several intralaminar thalamic nuclei in the lateral hypothalamus. These fibers are mostly distributed dorsolaterally to the fornix, in the region containing melanin concentrating hormone and orexin $(\mathrm{H} / \mathrm{O})$ neurons. This pathway probably represents a likely candidate for the rIPAG to control foraging activity $(28,29)$

\section{References}

1. Numan M. The physiology of reproduction. In: Knobil E, Neill JD (Editors), Maternal behavior. 2nd edn. New York: Raven Press; 1994. p 221-302.

2. Lonstein JS, Stern JM. Site and behavioral specificity of periaqueductal gray lesions on postpartum sexual, maternal, and aggressive behaviors in rats. Brain Res 1998; 804: 2135.

3. Felicio LF, Mazzini BK, Cacheiro RG, Cruz TN, Florio JC, Nasello AG. Stimulation of either cholecystokinin receptor subtype reduces while antagonists potentiate or sensitize a morphine-induced excitatory response. Peptides 2001; 22: 1299-1304.

4. Kinsley $\mathrm{CH}$, Bridges RS. Parity-associated reductions in behavioral sensitivity to opiates. Biol Reprod 1988; 39: 270278.

5. Mann PE, Kinsley CH, Ronsheim PM, Bridges RS. Longterm effects of parity on opioid and nonopioid behavioral and endocrine responses. Pharmacol Biochem Behav 1989; 34: 83-88.

6. Mann PE, Kinsley CH, Bridges RS. Opioid receptor subtype involvement in maternal behavior in lactating rats. Neuroendocrinology 1991; 53: 487-492.

7. Bridges RS, Grimm CT. Reversal of morphine disruption of maternal behavior by concurrent treatment with the opiate antagonist naloxone. Science 1982; 218: 166-168.

8. Felicio LF, Mann PE, Bridges RS. Intracerebroventricular cholecystokinin infusions block beta-endorphin-induced disruption of maternal behavior. Pharmacol Biochem Behav 1991; 39: 201-204.

9. Mann PE, Felicio LF, Bridges RS. Investigation into the role of cholecystokinin (CCK) in the induction and maintenance and supports the notion that enhanced locomotor behavior is not a simple increased generalized motor activity but a motivational drive towards food searching (30).

This hypothesis is supported by the fact that morphinetreated dams engaged in exploratory activities in detriment of those behaviors involving maternal choices such as nest building and retrieving. This did not happen for kyphosis, a reflex parameter attributed to another PAG area.

The present study demonstrated the disruption of FMB, suggesting the involvement of an opioidergic modulation of maternal behaviors through the rIPAG. Since it is known that this area drives behaviors, in a context of choice between foraging and maternal care, there might be a role for the rIPAG in the selection of adaptive behavioral mechanisms for the species.

\section{Acknowledgments}

The authors thank Dr. Cindy Bukach, Dr. Sandra Regina Mota Ortiz and Dr. Maria Isabel Roth de Carvalho Freitas for proofreading the manuscript. Research supported by FAPESP. of maternal behavior in rats. Horm Behav 1995; 29: 392406.

10. Miranda-Paiva CM, Felicio LF. Differential role of cholecystokinin receptor subtypes in opioid modulation of ongoing maternal behavior. Pharmacol Biochem Behav 1999; 64: 165-169.

11. Slamberova R, Szilagyi B, Vathy I. Repeated morphine administration during pregnancy attenuates maternal behavior. Psychoneuroendocrinology 2001; 26: 565-576.

12. Rubin BS, Bridges RS. Disruption of ongoing maternal responsiveness in rats by central administration of morphine sulfate. Brain Res 1984; 307: 91-97.

13. Kinsley $\mathrm{CH}$, Morse AC, Zoumas C, Corl S, Billack B. Intracerebroventricular infusions of morphine, and blockade with naloxone, modify the olfactory preferences for pup odors in lactating rats. Brain Res Bull 1995; 37: 103-107.

14. Tsukahara S, Yamanouchi K. Neurohistological and behavioral evidence for lordosis-inhibiting tract from lateral septum to periaqueductal gray in male rats. J Comp Neurol 2001; 431: 293-310.

15. Vianna DM, Brandao ML. Anatomical connections of the periaqueductal gray: specific neural substrates for different kinds of fear. Braz J Med Biol Res 2003; 36: 557-566.

16. Keay KA, Feil K, Gordon BD, Herbert H, Bandler R. Spinal afferents to functionally distinct periaqueductal gray columns in the rat: an anterograde and retrograde tracing study. $J$ Comp Neurol 1997; 385: 207-229.

17. Yaksh TL, Yeung JC, Rudy TA. Systematic examination in the rat of brain sites sensitive to the direct application of morphine: observation of differential effects within the periaqueductal gray. Brain Res 1976; 114: 83-103. 
18. Miranda-Paiva CM, Ribeiro-Barbosa ER, Canteras NS, Felicio LF. A role for the periaqueductal grey in opioidergic inhibition of maternal behaviour. Eur J Neurosci 2003; 18: 667-674.

19. Paxinos G, Watson C. The rat brain in stereotaxic coordinates. 2nd edn. San Diego: Academic Press Inc.; 1986.

20. Sukikara MH, Mota-Ortiz SR, Baldo MV, Felicio LF, Canteras NS. A role for the periaqueductal gray in switching adaptive behavioral responses. J Neurosci 2006; 26: 2583-2589.

21. Lonstein JS, De Vries GJ. Maternal behaviour in lactating rats stimulates c-fos in glutamate decarboxylase-synthesizing neurons of the medial preoptic area, ventral bed nucleus of the stria terminalis, and ventrocaudal periaqueductal gray. Neuroscience 2000; 100: 557-568.

22. Lonstein JS, Stern JM. Role of the midbrain periaqueductal gray in maternal nurturance and aggression: c-fos and electrolytic lesion studies in lactating rats. J Neurosci 1997; 17: 3364-3378.

23. Teodorov E, Tomita AT, Banon GP, Gil IG, Bernardi MM, Felicio LF. Behavioral effects of acute stimulation of kappaopioid receptors during lactation. Pharmacol Biochem Behav 2008; 90: 534-539.

24. Teodorov E, Modena CC, Sukikara MH, Felicio LF. Preliminary study of the effects of morphine treatment on opioid receptor gene expression in brain structures of the female rat. Neuroscience 2006; 141: 1225-1231.

25. Miranda-Paiva CM, Canteras NS, Sukikara MH, Nasello AG, Mackowiak II, Felicio LF. Periaqueductal gray cholecystokinin infusions block morphine-induced disruption of maternal behavior. Peptides 2007; 28: 657-662.

26. Sukikara MH, Platero MD, Canteras NS, Felicio LF. Opiate regulation of behavioral selection during lactation. Pharmacol Biochem Behav 2007; 87: 315-320.

27. Comoli E, Ribeiro-Barbosa ER, Canteras NS. Predatory hunting and exposure to a live predator induce opposite patterns of Fos immunoreactivity in the PAG. Behav Brain Res 2003; 138: 17-28.

28. Mota-Ortiz SR, Bittencourt JC, Elias CF, Canteras NS. Ascending projections from the rostral lateral periaqueductal gray (rIPAG): A critical site for controlling foraging behavior. Proceedings of the International Behavioral Neuroscience. Abstract 16. Rio de Janeiro, Brazil, June 12-16, 2007.

29. Sukikara MH, Baldo MV, Felício LF, Elias CF, Bittencourt JC, Canteras NS, et al. The role of rostrolateral periaqueductal gray (rIPAG) in a motivacional drive for food seeking behavior. Proceedings of the Society for Neuroscience 2009; $p$ S-6511.

30. Saper CB, Chou TC, Elmquist JK. The need to feed: homeostatic and hedonic control of eating. Neuron 2002; 36 : 199-211. 